\title{
Lifestyle Pattern and Knowledge about Diabetes Mellitus
}

\author{
Kartick Chanda Shaha *1, Shima Akhter Khatun ${ }^{2}$, Nafisa Mustafa ${ }^{3}$, \\ Farzana Ahmed ${ }^{4}$, Mohammed Asaduzzaman Khan ${ }^{5}$
}

\begin{abstract}
Introduction:The aim of the present study was to assess the pattern of lifestyle and knowledge about diabetes mellitus among type 2 diabetic patients at two tertiary level hospitals in Mymensingh. Materials and Methods: $A$ descriptive, cross sectional study was conducted from July 2015 to December 2015 among 300 patients attending at Medicine outpatient department of the Community Based Medical College Hospital and Endocrine outpatient department of the Mymensingh Medical College Hospital after obtaining requisite consent from the patients. Data were collected through the interviewing of the patients. The collected data were entered into the computer and analyzed by using SPSS version 20.1. The study was approved by the institutional ethical committee. Results: In a pool of 300 type 2 diabetics, Most of the patients $(57.3 \%)$ belonged to the middle age group 41-60 years. More than half of the respondents were female $(n=223,74.3 \%)$. 97\% patients were found to have knowledge about timing of dose regimen. Majority of patient's (35.7\%) knowledge about hypoglycemia was poor. The rate of adherence to diet was 51\%. The rate of adherence to exercise was $68.3 \%$. Conclusion: Majority of type 2 DM patients displayed optimal level of diabetes knowledge. There was a high rate of non adherence to diet and exercise recommendations by patients suffering from type 2 diabetes mellitus. So continuous patient education and awareness program are required.
\end{abstract}

Keywords: Lifestyle pattern, Diabetes mellitus.

Number of Tables: 02; Number of Figures: 02: Number of References: 10; Number of Correspondences: 05

*1. Corresponding Author:

Dr. Kartick Chanda Shaha

Assistant Professor

Department of Pharmacology

Dhaka National Medical College.

Email: Kartick_shaha@yahoo.com

Mobile: 01672971352

2. Dr. Shima Akhter Khatun

Assistant Professor

Department of Pharmacology

Dhaka National Medical College

3. Dr. Nafisa Mustafa

Assistant Professor

Department of Pharmacology

Dhaka National Medical College

4. Dr. Farzana Ahmed

Assistant Professor

Department of Pharmacology

Dhaka National Medical College

5. Dr. Mohammed Asaduzzaman Khan

Assistant Professor

Department of Respiratory Medicine

Dhaka National Medical College

\section{Introduction}

Diabetes mellitus is the chronic disorder emerging as a major world health problem which increases the rate of morbidity and mortality. It is associated with abnormal carbohydrate, protein and lipid metabolism. The prevalence of diabetes mellitus is growing rapidly worldwide and is reaching epidemic proportions $^{1}$. It is estimated that there are currently 422 million people with diabetes worldwide and this number is set to double in the next 20 years $^{2}$. Because of the progressive nature of the disease, an evolving treatment strategy is necessary to maintain both fasting and postprandial glycemic control. Diabetes care aims at improving the quality of life of patients with type 2 diabetes through good glycemic control, lifestyle modification, and diabetes education ${ }^{3}$. Regular physical activity plays a significant role in diabetes management. Through regular physical exercise, the need for insulin injections or oral medications can often be reduced. Regular physical activity also helps with weight loss as well as controlling blood cholesterol and blood pressure. Healthy dietary pattern has a beneficial effect on human health and regarding the treatment of type 2 diabetes mellitus. Healthy dietary pattern will help to control: Blood glucose levels, blood fat cholesterol and triglycerides and blood pressure. There is no cure for diabetes. However, Type 2 diabetes can be prevented by changes in the lifestyles of high-risk subjects ${ }^{4}$. Diabetes education is the cornerstone of diabetes care. Improved training of the primary health care providers and patients with diabetes is therefore beneficial ${ }^{3}$.

\section{Materials \& Methods}

A descriptive, cross sectional study was conducted from July 2015 to December 2015 among 300 patients attending at medicine outpatient department of the Community Based Medical College Hospital and Endocrine outpatient department of the Mymensingh Medical College Hospital after obtaining requisite consent from the patients. Purposive sampling was adopted for collecting data. The study was approved by the institutional ethical committee. The interviews were held directly in the corridor just outside the Outpatient Department. The relevant information was entered into the predesigned proforma to know the pattern of lifestyle and knowledge about diabetes mellitus among type 2 diabetic patients. The collected data were entered into the computer and analyzed by using SPSS (version 20.1) 


\section{Results}

The age structures of the patients have been categorized in years into three groups. Overall $77(25.7 \%)$ patients were in $\leq 40$ years old while $172(57.3 \%)$ patients were $41-60$ years old, $51(17.0 \%)$ patients belong to $>60$ years' age group. Total numbers of patients both male and female were 300. It comprised of $77(25.7 \%)$ male and 223 $(74.3 \%)$ female in outpatient. Out of 300 patients, 197 patients came from urban area and 103 patients from rural area. Out of 300 patients, $152(50.7 \%)$ were illiterate, 72 $(24.0 \%)$ had primary education, $25(8.3 \%)$ had junior education, $21(7.0 \%)$ had secondary education, $15(5.0 \%)$ had higher secondary education and $15(5.0 \%)$ had tertiary education (Table-I).

Table-I: Demographic characteristics of the study population $(n=300)$.

\begin{tabular}{lcc}
\hline Parameters & Number & Percentage \\
\hline Age of the patients & & \\
\hline$\leq 40$ years & 172 & 25.7 \\
41-60 years & 51 & 57.3 \\
$>60$ years & 300 & 17.0 \\
\hline Total & & 100.0 \\
\hline Sex & 77 & \\
Male & 223 & 74.3 \\
Female & 300 & 100 \\
\hline Total & & \\
\hline Residence & 197 & 65.7 \\
\hline Urban & 103 & 34.3 \\
Rural & 300 & 100 \\
\hline Total & & \\
\hline Educational status & 72 & 24.0 \\
\hline Primary & 25 & 8.3 \\
Junior & 21 & 7.0 \\
Secondary & 15 & 5.0 \\
Higher secondary & 15 & 5.0 \\
Graduated & & 50.7 \\
Illiterate & & \\
\hline Total & & \\
\hline
\end{tabular}

According to figure-1, 153 patients (51\%) maintained diabetic diet chart regularly.

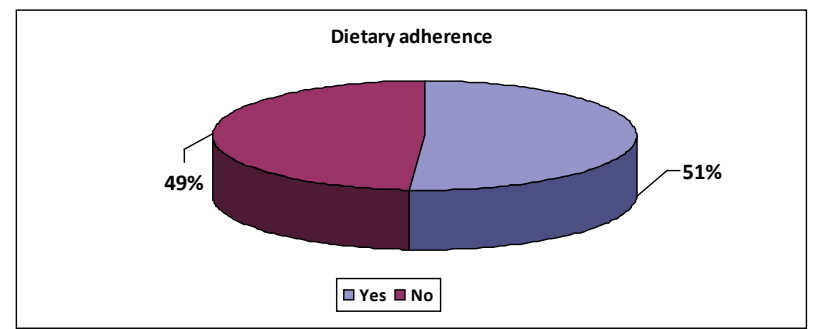

Figure-1: Pie chart showing pattern of dietary adherence of the study population.
According to figure-2, 205 patients $(68.3 \%)$ took physical exercise regularly.

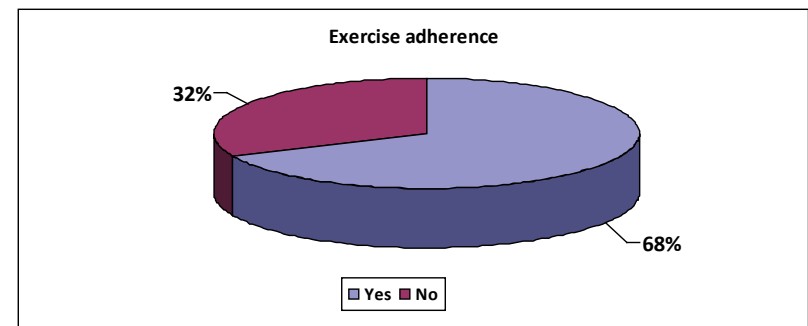

Figure-2: Pie chart showing pattern of exercise adherence of the study population

291 patients (97\%) were found to have knowledge about timing of dose regimen. 107 patients (35.7\%) knew the actions to take in case of hypoglycemia (Table-II).

Table-II: Distribution of patient's knowledge on various aspect of DM ( $=300)$.

\begin{tabular}{lcc}
\hline Knowledge on & Number & $\begin{array}{c}\text { Correct response } \\
\text { (Percentage) }\end{array}$ \\
\hline $\begin{array}{l}\text { Knowledge about timing of dose } \\
\text { regimen } \\
\begin{array}{l}\text { Measure to take in case of } \\
\text { hypoglycemia }\end{array}\end{array}$ & 291 & 97.0 \\
\hline
\end{tabular}

\section{Discussion}

This study showed that diabetes mellitus is more prevalent in female patients than in male patients. Similar results were obtained in the study conducted by Alam et al. (2014), Mann et al. (2009) and Abebaw et al. (2016) 5,6,7. This study also found a higher prevalence of diabetes was among middle aged patients, with a high percentage $(57.37 \%)$ in the age group of 41-60 years. This result correlates with the study of sajith et al. (2014) ${ }^{1}$. In the present study, type 2 $\mathrm{DM}$ is more common in urban people (34.3\%). Our study findings are also similar to the study conducted in Bangladesh by Akter et al. (2014) ${ }^{8}$. In our study, majority, $214(71.3 \%)$, of the participants were housewives and service holder, $27(9.0 \%)$. This present study correlates with the study of Abebaw et al. (2015) but the percentage is not same ${ }^{7}$. In their study they observed that majority, 98 $(34 \%)$, of the participants were housewives and government employee, 50 (17.4\%). In this study, 97\% patients were found to have knowledge about timing of dose regimen which is higher than the number (90\%) reported by Shrestha et al. (2013) study ${ }^{9}$. In this study $35.7 \%$ patients knew the action to take in case of hypoglycemia which is lower than the number $(100 \%)$ reported by Prasad ${ }^{10}$. In the present study the rates of adherence to diet and exercise were $51 \%$ and $68.3 \%$ respectively. This study results are not consistent with the results of the sajith et al. (2014) study. In their study they observed that $3.81 \%$ and $32.29 \%$ respectively of all patients were belonging to dietary and exercise adherence ${ }^{1}$. 


\section{Conclusion}

Type 2 diabetes mellitus being a chronic disorder requires multiple therapeutic approaches including dietary and lifestyle modifications. There was a high rate of non adherence to diet and exercise recommendations by patients suffering from type 2 diabetes mellitus at Mymensingh, Bangladesh. Majority of type 2 DM patients displayed optimal level of diabetes knowledge. We strongly feel that there is a need to design and develop individualized diabetes educational program that could help in diabetes management and improvement of quality of life.

Conflict of Interests: None.

\section{Acknowledgement}

The authors are grateful to the entire staff of the medical outpatient department of the Mymensingh Medical College Hospital and Community Based Medical College Hospital, Mymensingh for their cooperation and support during the study period.

\section{References}

1. Sajith, M., Pankaj, M., Pawar, A., et al. Medication adherence to anti-diabetic therapy in patients with type 2 diabetes mellitus. International jounal of pharmacy and pharmaceutical science. 2014: 6(2): 564-570.

2. World Health Day 2016: Beat diabetes, Available from: http://www.who.int/campaigns/world-health-day/2016

3. Naheed gul. Knowledge, Attitudes and Practices of type 2 diabetic patients. J Ayub Med Coll Abbottabad. 2010: 128-131.

4. Asif, M. Information on the effects of physical workout and diet on diabetic patients. Afr J Med Health. 2013; 12(1): 38-43.

https://doi.org/10.4103/2384-5589.129923

5. Alam, M.S., Aqil, M., Qadry, S.A.S., et al. Utilization pattern o oral hypoglycemic agents for diabetes mellitus type 2 patients attending out patient department at a university hospital in new Delhi. Pharmacology and pharmacy. 2014; 5: 636-645.

https://doi.org/10.4236/pp.2014.57073

6. Mann, D.M., Ponieman, D., Leventhai. H. et al. Predictors of adherence to diabetes medications: the role of disease and medication beliefs. J Behav Med. 2009; 32: 278-284.

https://doi.org/10.1007/s10865-009-9202-y

PMid: 19184390

7. Abebaw, M., Messele, A., Hailu, M., et al. Adherence and associated factors towards anti-diabetic medication among type 2 diabetic patients on follow up at university of Gondar hospital, northwest Ethiopia. Advances in nursing. 2016: 7. Article ID 8579157

https://doi.org/10.1155/2016/8579157

8. Akter, S., Rahman. M.M., Abe, S.K., et al. Prevalence of diabetes and prediabetes and their risk factors among Bangladeshi adults: a nationalwide survey. Bull world health organ. 2014; 92: 204-213A.

https://doi.org/10.2471/BLT.13.128371

PMid:24700980 PMCid:PMC3949596

9. Shrestha, SS., Shakya, R., Karmacharya, BM., et al. Medication adherence to oral hypoglycemic agents among type 2 diabetic patients and their clinical outcomes with special reference to fasting blood glucose and glycosylated haemoglobin levels. Kathmandu university medical journal. 2013; 43(3): 226-232.

https://doi.org/10.3126/kumj.v11i3.12510

10. Prasad, S.S. "Type 2 Diabetes - Patients' Knowledge On Diabetes, Its Medications and Complications At Outpatient Pharmacy, Colonial War Memorial Hospital", Fiji national university, College of medicine, nursing and health science. 2014; available from: health.gov.fj/fijihrp/index.php? journal $=$ hrp\&page $=$ search\&op. 228 . 